\title{
Numerical Analysis of Unsteady Cavitating Vortex around Two-dimensional Wedge-shaped Submerged Body
}

\author{
Ji-Hye Kim*, So-Won Jeong*, Byoung-Kwon Ahn®*, Chul-Soo Park* and Gun-Do Kim ${ }^{* *}$ \\ "Naval Architecture and Ocean Engineering, Chungnam National University, Daejon, Korea \\ "Korea Research Institute of Ships and Ocean Engineering, Daejon, Korea
}

\section{2차원 쐐기형 몰수체의 비정상 공동 와류에 대한 수치해석}

\author{
김지혜 ${ }^{*}$ - 정소원 ${ }^{*}$ - 안병권 ${ }^{*}$ - 박철수 ${ }^{* *}$ 김건도 \\ "충남대학교 선박해양공학과 \\ *한국해양연구원 선박해양플랜트연구소
}

KEY WORDS: Cavitating flow 공동유동, Multiphase flow 다상유동, Wake flow 후류 유동, Vortex 와류

ABSTRACT: Unlike a slender body, vortices are shed off alternately in the wake of a blunt body. In the case of liquid flows, when the pressure falls below the vapor pressure, cavitation occurs in the vortex core and affects the formation of the vortex street. This phenomenon is of major importance in many practical cases because the alternate shedding of vortices creates imbalanced forces on the body. Hence, it is very important to determine the shedding frequency of cavitating vortices. In this paper, the unsteady cavitating flow around a two-dimensional wedge-shaped submerged body was simulated using the commercial code STAR-CCM+. A numerical investigation of the structure of cavitating vortices was performed for a model with an apex angle of $20^{\circ}$. The results were validated by comparing them with experimental measurements carried out at a cavitation tunnel of Chungnam National University (CNU-CT). It was found that the shedding frequency of the vortex increased by up to 18\%, which was strongly affected by the development of cavitation.

\section{1. 서 론}

수중운동체의 속도가 빨라짐에 따라 운동체 주위의 압력이 증기압 이하로 감소하게 되면, 액체가 기체로 변화는 캐비테이 션 현상이 발생하게 된다. 발생한 기포가 성장하여 수중운동체 를 모두 뒤덮게 되면 운동체는 물과 직접적으로 접촉하는 면적 이 감소함에 따라 마찰저항의 영향을 거의 받지 않게 되고, 이 로 인해 동일한 연료 대비 극적인 속도 증가 효과를 얻을 수 있 다. 이러한 초공동(Supercavitation) 현상을 이용한 수중운동체에 대한 기초연구가 국내에서 활발히 이루어지고 있으며(Ahn, et al., 2010; Ahn, et al., 2012; Kim, et al., 2013; Kim, et al., 2016), 초공동을 발생시키는 기술뿐만 아니라 초공동 수중운동체의 제 어를 위한 기초 연구도 함께 수행되어오고 있다. 초공동 수중운 동체의 제어를 위해 사용하는 제어핀은 일반적으로 쐐기 형상 의 단면을 갖으며 수중운동체의 자세와 심도를 변화시키는 역
할을 한다. 수중운동체의 속도가 증가함에 따라 일정 속도 이상 의 영역에서는 초공동을 발생시키는 캐비테이터(Cavitator)뿐만 아니라 제어핀의 후류에서도 공동이 성장하게 되는데, 이때, 상 대적으로 무딘 물체(Blunt body)의 후류에서 나타나는 주기적인 와류(Periodic vortex)가 발생하게 된다. 비공동 상태에서 발생하 는 이러한 와류 특성에 관해서는 실험 또는 수치적인 연구가 활발히 수행되어 왔으나(Ramamurthy and Balachandar, 1990; Ozgoren, et al., 2015), 공동 생성 이후 발생하는 와류의 특성에 대한 연구는 미흡한 실정이다. Belahadji, et al.(1995)은 2차원 쐐 기 후류 유동장을 유동 특성에 따라 분류하고, 2차원 쐐기 후류 에 공동이 생성되었을 경우 발생하는 와류의 형상 및 주기적인 특성을 평가하였다. 국내에서는 2차원 쐐기형 제어핀 후류에서 발생하는 공동유동 특성을 살피기 위하여 충남대학교 캐비테이 션 터널에서 초고속 카메라를 이용하여 유동장을 면밀히 관측 하고 유동장 내 변동압력을 계측하여 2차원 쐐기형 제어핀 후

Received 19 December 2017, revised 18 January 2018, accepted 1 February 2018

Corresponding author Byoung-Kwon Ahn: +82-42-821-6625, bkahn@cnu.ac.kr, ORCID: https://orcid.org/0000-0002-0339-6069 It is noted that this paper is revised edition based on proceedings of SNAK 2017 in Yeosu 
류 유동의 주기적인 특성을 확인한 바 있다(Jeong and Ahn, 2016). 본 연구에서는 상용프로그램인 STAR-CCM+를 사용하여 2차원 쐐기 후류의 비정상 공동유동을 해석하였으며, 다양한 조 건에서 발생하는 공동의 형상정보 및 유동장의 변동 압력 계산 을 통해 공동의 발생이 후류의 주기적인 와류 특성에 미치는 영향을 평가하였다. 또한, 이를 충남대학교 캐비테이션 터널에 서 수행한 실험 결과와 비교하여 검증하고자 하였다.

\section{2. 지배방정식 및 수치해석 기법}

\section{1 지배방정식}

2 차원 쐐기 주위의 비정상 공동유동 해석을 위하여 검사체 적 내의 각 셀(Cell)은 다음의 연속방정식과 운동량방정식, 즉 RANS(Reynolds averaged navier-stokes) 방정식을 포함하는 지배 방정식을 만족한다. 또한, 물과 수증기로 이루어진 다상유동 (Multiphase flow) 해석을 위하여 상계면(Phase interface)을 추적 하는 방법으로 VOF(Volume of fluid) 방법을 적용하였으며, 이 를 위해 식 (3)의 체적분율 방정식을 해석한다.

$$
\begin{aligned}
& \frac{\partial \rho}{\partial t}+\frac{\partial u_{j}}{\partial x_{j}}=0 \\
& \frac{\partial}{\partial t}\left(\rho u_{j}\right)+\frac{\partial}{\partial x_{j}}\left(\rho u_{i} u_{j}\right)=-\frac{\partial P}{\partial x_{j}}+\mu \frac{\partial}{\partial x_{i}}\left(\frac{\partial u_{i}}{\partial x_{j}}+\frac{\partial u_{j}}{\partial x_{i}}\right)+F_{j} \\
& \frac{\partial}{\partial t}\left(\rho_{q} \alpha_{q}\right)+\frac{\partial}{\partial x_{j}}\left(\rho_{q} \alpha_{q} u_{j}\right)=S_{\alpha_{q}}+\sum_{q=1}^{n}\left(\dot{m}_{p q}-\dot{m}_{q p}\right)
\end{aligned}
$$

여기서, $i, j, k$ 는 좌표계를, $p$ 와 $q$ 는 혼합 유체 내에 존재하는 상(Phase)을 나타내고 각각의 상은 동일한 속도 $(u)$ 와 압력 $(P)$ 을 갖으며 $F$ 는 외력항을 나타낸다. 공동유동은 물과 수중기로 이 루어진 이상유동(Two-phase flow)으로 상의 개수 $n=2$ 이다. 이 때, 식 (1)과 식 (2)의 밀도 $(\rho)$ 와 점성계수 $(\mu)$ 는 다음과 같이 각 각의 상에 대한 체적분율(Volume fraction) $\alpha$ 로 정의할 수 있으 며, $\alpha$ 는 $0 \sim 1$ 의 값을 갖는다.

$$
\begin{aligned}
& \rho=\sum_{q=1}^{2} \alpha_{q} \rho_{q} \\
& \mu=\sum_{q=1}^{2} \alpha_{q} \mu_{q}
\end{aligned}
$$

식 (3)에서 $S_{\alpha_{q}}$ 는 체적분율에 대한 소스항이며, 2차상(Secondary phase)인 수증기에 대해 방정식을 먼저 해석하고, 식 (6)을 이용 하여 1차상(Primary phase)인 물에 대하여 방정식을 해석한다.

$$
\sum_{q=1}^{2} \alpha_{q}=1
$$

\section{2 캐비테이션 모델}

공동유동 해석을 위하여 다음 식 (7)로 나타나는 수증기의 체적 분율에 대한 수송방정식을 풀게 된다. 여기서 $v$ 는 수증기를 나타내
며, $R_{e}$ 와 $R_{c}$ 는 각각 기포의 기화(Evaporation)와 응축(Condensation) 을 나타내는 소스항이다.

$$
\frac{\partial}{\partial t}\left(\rho_{v} \alpha_{v}\right)+\frac{\partial}{\partial x_{j}}\left(\rho_{v} \alpha_{v} u_{j}\right)=R_{e}-R_{c}
$$

캐비테이션 해석을 위해 다양한 모델들이 제시되어 왔으며, 본 연구에서는 Schnerr-Sauer 모델(Schnerr and Sauer, 2001)을 적 용하였다. Schnerr-Sauer 모델은 기존의 Rayleight-Plesset 방정식 을 단순화한 형태로 기포의 성장 가속도, 점성 효과, 그리고 표 면 장력의 영향을 무시한다. 해당 모델에서 제시하는 소스항과 기포 직경 $\left(R_{B}\right)$ 은 다음 식 (8)-(10)과 같다. 이때, $p_{v}$ 는 증기압 (Vapor pressure)을 나타내며, $n_{b}$ 는 단위체적당 기포수, 그리고 $\rho_{v}$ 와 $\rho_{l}$ 은 각각 공기와 물의 밀도를 나타낸다.

$$
\begin{aligned}
& R_{e}=\frac{\rho_{v} \rho_{l}}{\rho} \alpha_{v}\left(1-\alpha_{v}\right) \frac{3}{R_{B}} \sqrt{\frac{2}{3} \frac{p_{v}-p}{\rho_{l}}},\left(p \leq p_{v}\right) \\
& R_{c}=\frac{\rho_{v} \rho_{l}}{\rho} \alpha_{v}\left(1-\alpha_{v}\right) \frac{3}{R_{B}} \sqrt{\frac{2}{3} \frac{p-p_{v}}{\rho_{l}}},\left(p \geq p_{v}\right) \\
& R_{B}=\left(\frac{\alpha_{v}}{1-\alpha_{v}} \frac{3}{4 \pi} \frac{1}{n_{b}}\right)^{\frac{1}{3}}
\end{aligned}
$$

\section{3 수치해석 기법}

2차원 쐐기 후류의 공동유동 특성에 대한 수치해석을 위해 상용프로그램인 STAR-CCM+ (ver.11.06)를 사용하였다(Siemens, 2016). 지배방정식의 확산항 및 대류항, 그리고 시간 적분은 2차 정확도로 이산화하였고, 속도와 압력은 SIMPLE(Semi-implicit method for pressure linked equations) 알고리즘을 사용하여 해석 하였다. 난류모델은 Realizable k-epsilon 모델을 적용하였고, 쐐 기 및 캐비테이션 터널의 벽면에 대한 경계조건 처리를 위하여 벽함수를 사용하였다.

\section{3. 수치해석 조건 및 결과}

\section{1 수치해석 조건}

계산 영역 및 경계조건은 Fig. 1과 같으며, 이때 캐비테이션 터널의 폭은 $100 \mathrm{~mm}$ 이고 쐐기의 폭과 각도는 각각 $20 \mathrm{~mm}$ 와 $20^{\circ}$ 이다. 쐐기의 위치를 기준으로 상류 경계면, 하류 경계면 그리 고 캐비테이션 터널 벽면까지의 거리는 쐐기 폭의 약 10 배, 25 배, 그리고 3 배이다. 캐비테이션 터널 벽면에는 Slip-wall 조건을 적용하였다.

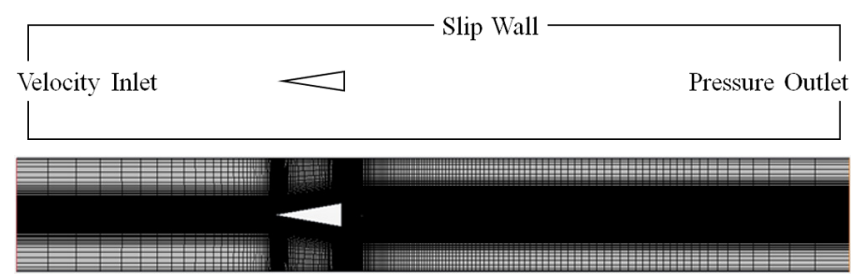

Fig. 1 Computation domain and grid system 
Table 1 Fluid properties

\begin{tabular}{ccc}
\hline \hline & Water & Vapor \\
\hline Temperature $\left[{ }^{\circ} \mathrm{C}\right]$ & \multicolumn{2}{c}{24.5} \\
Density $[\mathrm{kg} / \mathrm{m} 3]$ & 997.13 & 0.0224 \\
Dynamic viscosity $[\mathrm{Pa} \cdot \mathrm{s}]$ & $9.003 \times 10^{-4}$ & $9.8527 \times 10^{-6}$ \\
Saturation Pressure $[\mathrm{Pa}]$ & 3170.34 & \\
\hline
\end{tabular}

2차원 정렬 격자수는 6 8만개 사이에서 공동 및 비공동 상태 에 대하여 격자 민감도 테스트를 수행하였으며, 충분한 캐비테 이션의 모사를 위해 최종적으로 7만개의 격자로 계산을 수행하 였다. 이때 $y+$ 는 벽함수를 사용하는 조건으로 30 100으로 하였 고 비정상 해석을 위한 $\Delta t=10^{-5}$ 이며, 쐐기 주변 유동장의 최 소격자 기준으로 $\mathrm{CFL}$ (Courant-friedrichs-lewy) 조건은 1이 넘지 않도록 하였다. 또한, 충남대학교 캐비테이션터널(CNU-CT) 실 험과의 비교를 위하여 계산에 사용된 물과 수증기의 물성치는 다음 Table 1 과 같다.

\section{2 수치해석 결과}

공동의 발생정도는 다음 식 (11)로 정의된 캐비테이션수 $(\sigma)$ 를 사용하여 평가하였다. 여기서 $p_{\infty}$ 와 $V_{\infty}$ 는 유입유동의 압력과 속도를 나타낸다. 계산은 캐비테이션터널 시험조건과 동일하게 $R n=1.6 \times 10^{5}$ 에서 압력을 낮춰가며 수행하였고, 레이놀즈수 $(R n)$ 는 다음 식 (12)로 정의하며, 여기서 $d$ 는 쐐기의 폭, $\nu$ 는 동점성 계수를 나타낸다.

$$
\begin{array}{r}
\sigma=\frac{p_{\infty}-p_{v}}{\frac{1}{2} \rho V_{\infty}^{2}} \\
R n=\frac{V_{\infty} d}{\nu}
\end{array}
$$

Fig. 2는 캐비테이션수가 낮아짐에 따라 쐐기의 후류에서 공 동이 성장하는 모습을 보여준다. 충남대학교 캐비테이션터널 관측 결과와 수치해석을 통한 절대압력(Absolute pressure) 분포 를 동일한 캐비테이션수 조건에서 비교하였을 때 발생하는 공 동의 형상이 비교적 잘 일치함을 확인할 수 있다.

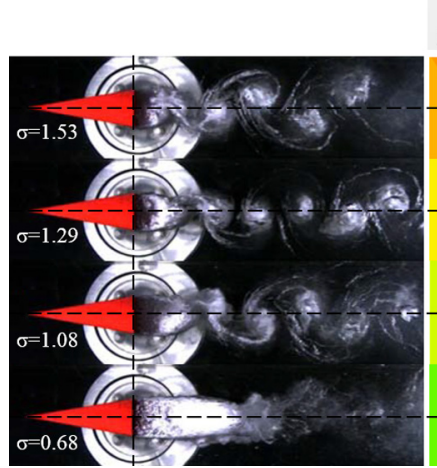

(a) Experimental observations

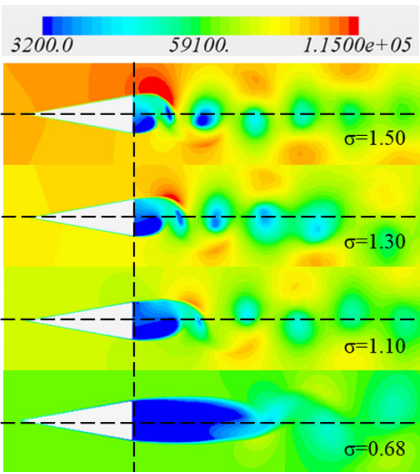

(b) Absolute pressure contours (STAR-CCM+)
Fig. 2 Comparison of wake cavitating flow

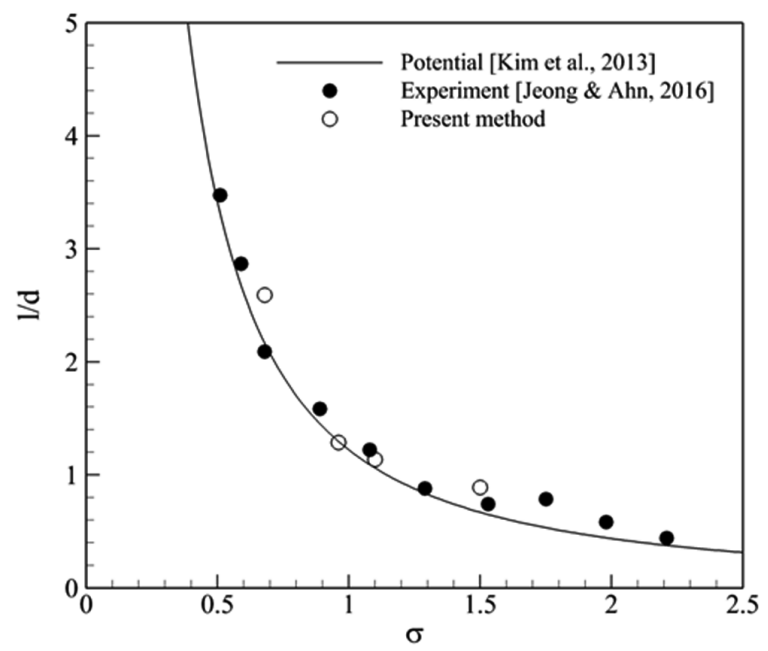

Fig. 3 Comparison of the cavity length according to the cavitation number

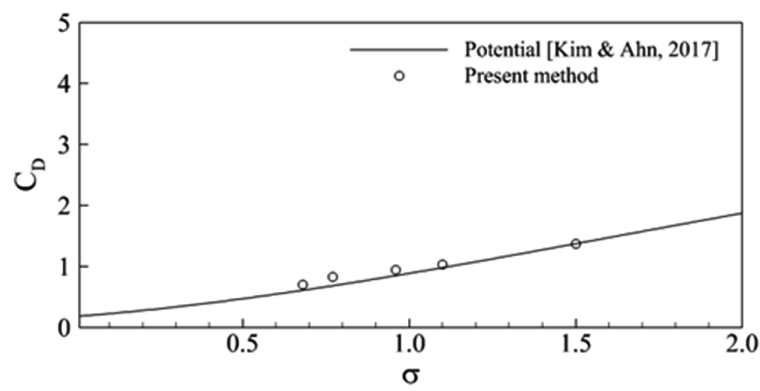

Fig. 4 Comparison of the drag coefficient according to the cavitation number

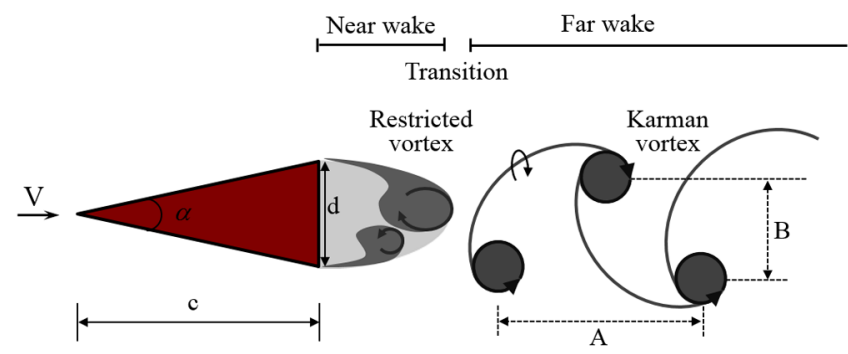

Fig. 5 Typical structure of the cavitating wake

발생한 공동의 형상 및 특성을 보다 면밀하게 검증하기 위하 여 수치해석을 통해 계산한 공동의 길이와 쐐기에 작용하는 항 력 특성을 실험(Jeong and Ahn, 2016) 및 비점성 해석법(Kim et al., 2013)을 통해 얻은 결과와 비교하여 평가하였다. Fig. 3과 Fig. 4의 비교 결과를 통해 캐비테이션수에 따라 발생한 공동의 무차원 길이 $(l / d)$ 와 쐐기에 작용하는 항력 계수 $\left(C_{D}\right)$ 가 해당 결과 와 잘 일치함을 알 수 있다. 특히, 본 연구에서는 쐐기 후류에서 발생하는 와류의 주기적인 거동 특성을 엄밀하게 평가하고자 하였다. 2차원 쐐기의 후류에서 형성되는 유동장은 Fig. 5 에 나 타난바와 같이 가까운 후류(Near wake)와 먼 후류(Far wake) 영 역으로 구분되며, 그 사이에 천이영역으로 구분할 수 있다. 쐐 기 끝단에서 박리되는 와류는 속도가 가속됨에 따라 일반적으 로 천이구간을 거치면서 와류의 중심에서 캐비테이션이 발생하 


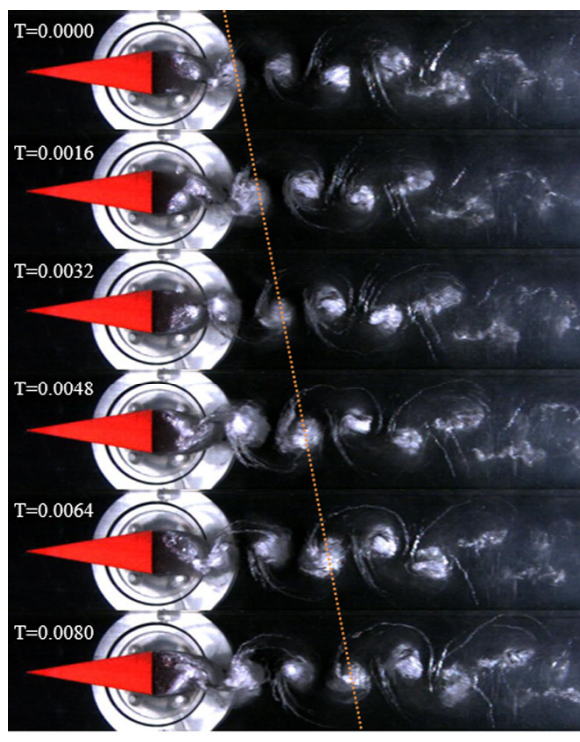

(a) Experimental observations

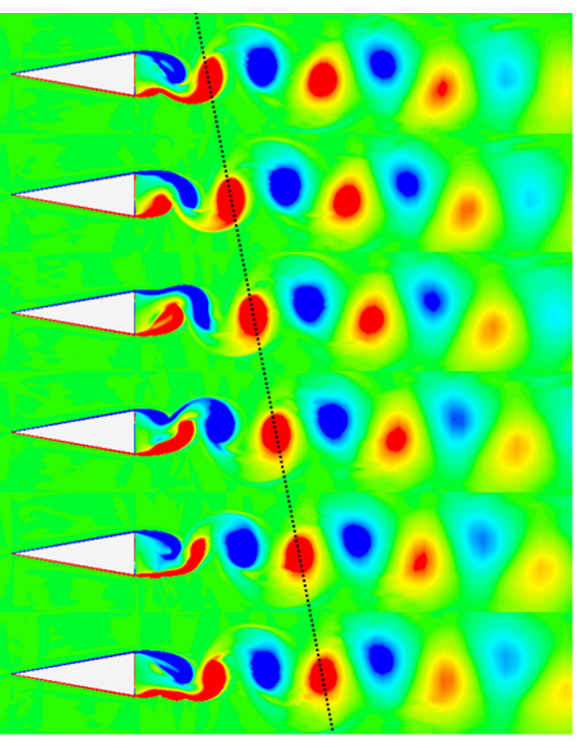

(b) Vorticity contours (STAR-CCM+)

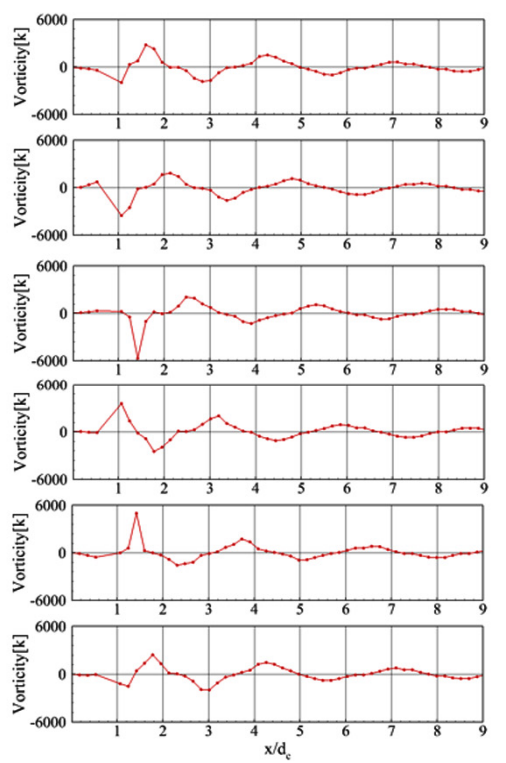

(c) Vorticity distributions (STAR-CCM+)

Fig. 6 Periodic motion of the Karman vortex street in the far wake region (cal. $\sigma=1.30$, exp. $\sigma=1.29$ )

게 되며, 먼 후류 영역에서 잘 알려진 Karman 와류의 발생을 야 기한다(Franc and Michel, 2004). 또한 캐비테이션수가 높을 때, 즉 공동의 길이가 짧은 조건에서는 쐐기 폭의 1 배 이전의 가까 운 후류 영역에서 Karman 와류와 주기적 특성이 다른 구속 와 류(Restricted vortex)가 존재한다.

먼저 먼 후류 영역에서 발생하는 Karman 와류의 주기적 특성 을 살펴보기 위하여 캐비테이션수 $\sigma=1.30$ 일 때, 시간에 따라 나타나는 2차원 쐐기 후류 유동 특성을 살펴보았다. 수치해석을 통해 와도(Vorticity $k, \min -600 / \mathrm{s}, \max 600 / \mathrm{s}$ ) 분포를 확인한 결 과(Fig. 6(b)), Karman 보텍스의 박리되는 주기가 0.008s로 나타 났으며 이는 동일한 조건의 실험결과(Fig. 6(a))와 비교하였을 때 해당 주기가 일치한다. 또한, 쐐기의 중심선을 따라 추출한 와도의 세기 분포가 해당 주기와 일치하게 반복됨을 확인하였 다(Fig. 6(c)).

보다 면밀한 비교를 위하여 기준이 되는 $T=0.000$ 초와 주기의 절반인 $T=0.004$ 초일 때의 수치해석 결과 중 와도(Vorticity $k$,
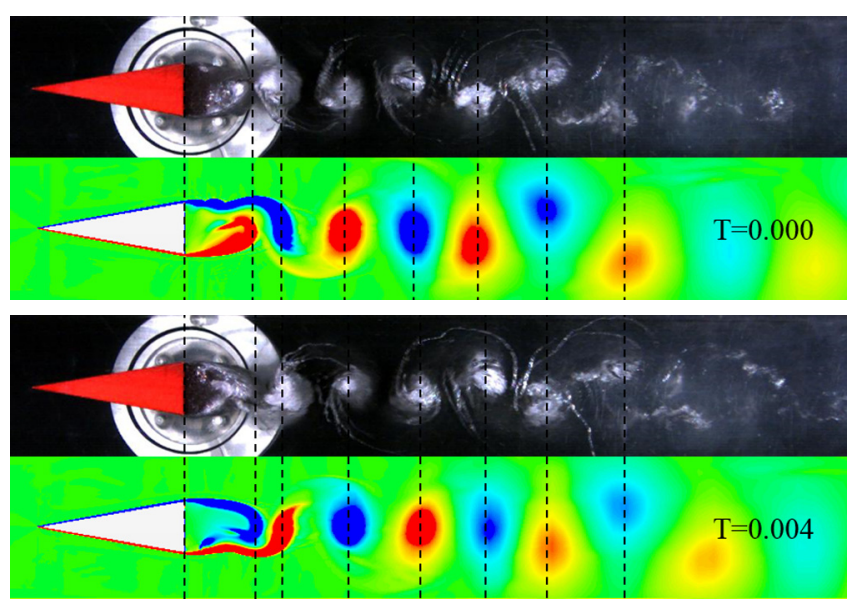

Fig. 7 Comparison of periodic motion of the Karman vortex (cal. $\sigma=1.30$, exp. $\sigma=1.29$ ) $\min -600 / \mathrm{s}, \max 600 / \mathrm{s}$ ) 분포를 실험 결과와 비교하였을 때, 각 시간별 Karman 와류의 박리 위치와 공동의 형상이 잘 일치하는 것을 확인할 수 있다(Fig. 7).

공동의 성장은 먼 후류에서 발생하는 Karman 와류의 형상에 도 영향을 미친다. 동일한 방향으로 회전하는 Karman 와류 사 이의 수평 거리를 $A$, 수직거리를 $B$ 라고 할 때(Fig. 5 참조), 캐비 테이션수 변화에 따른 두 거리의 비 $(B / A)$ 를 평가하였다(Fig. 8). 캐비테이션수가 감소함에 따라 와류 간의 수직거리는 감소하고 수평거리는 증가하여 거리비는 최대 $75 \%$ 까지 감소하는 것을 알 수 있으며, 실험 결과와 비교하여 잘 일치함을 확인하였다.

다음으로 가까운 후류 영역에서 발생하는 구속 와류의 주기적 특성을 살펴보기 위하여 앞서와 동일한 캐비테이션수 $\sigma=1.30$ 일 때, 시간에 따라 나타나는 2차원 쐐기 후류 유동 특성을 살펴보 았다. Fig. 9는 왼쪽부터 와도(Vorticity k, $\min -600 / \mathrm{s}, \max 600 / \mathrm{s}$ ), 압력(Absolute total pressure, $\min 3200 \mathrm{~Pa}, \max 1.15 \times 10^{5} \mathrm{~Pa}$ ), 수증기

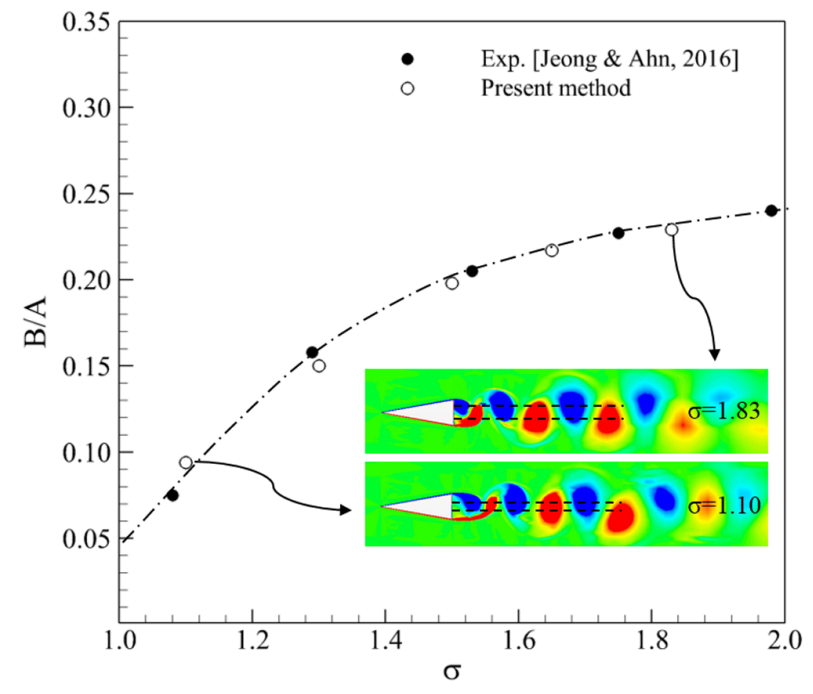

Fig. 8 Geometric characteristic of the vortex street 


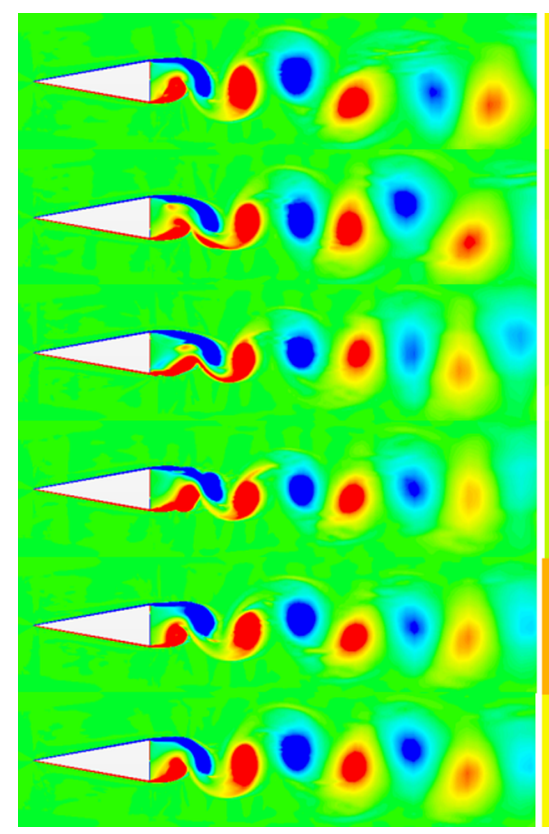

(a) Vorticity contours

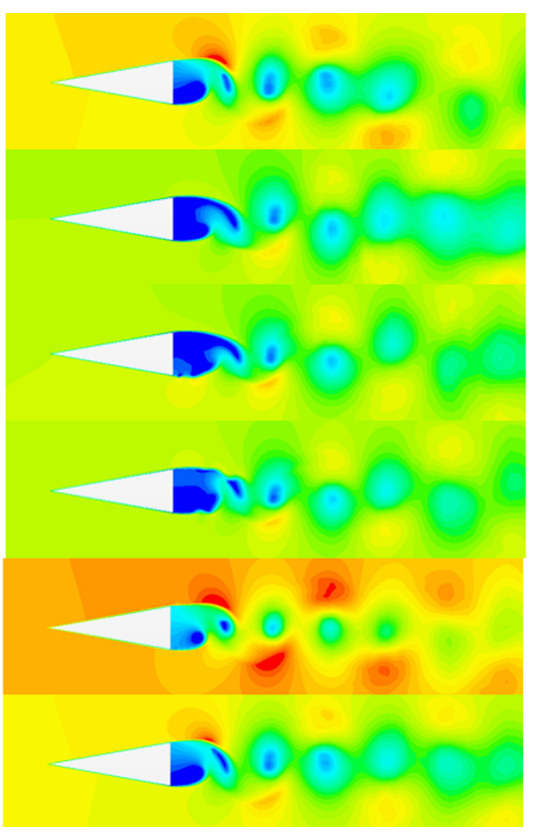

(b) Absolute pressure contours

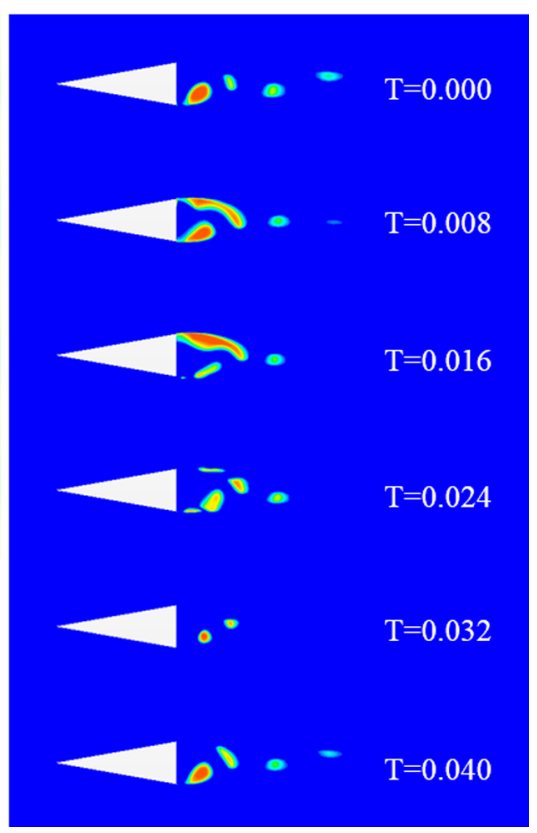

(c) Vapor volume fraction contours

Fig. 9 Periodic motion of the restricted vortex in the near wake region $(\sigma=1.30)$

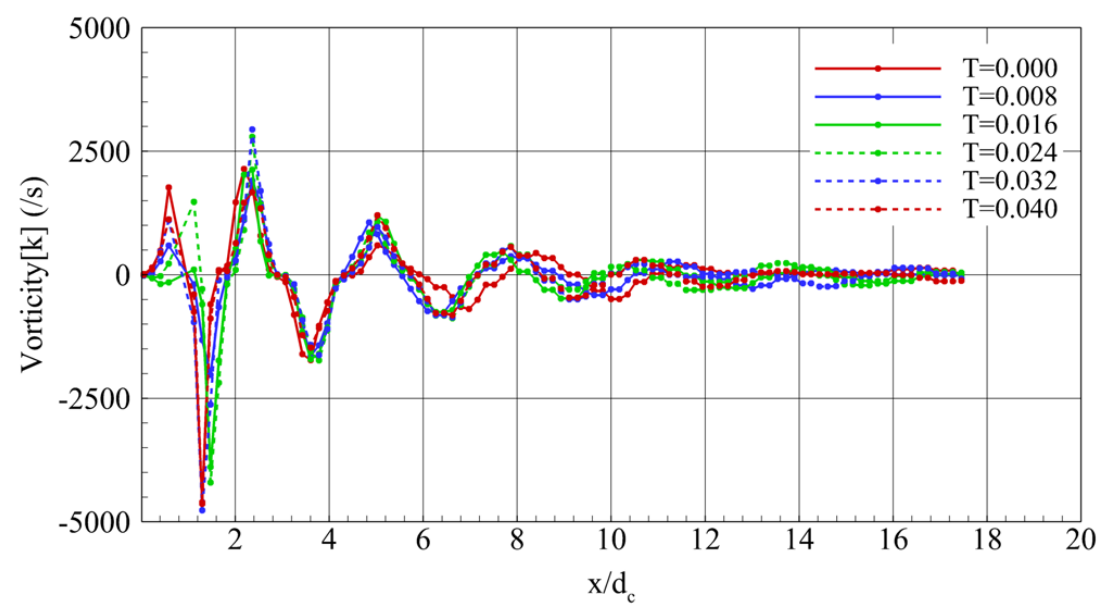

Fig. 10 Vorticity distributions along the center line of a wedge- shaped submerged body $(\sigma=1.30)$

체적분율(Vapor volume fraction, $\min 0, \max 1)$ 을 보여주며, 압력 과 수증기 체적분율 분포가 반복됨을 통해 구속 와류의 주기가 $T=0.04$ 임을 확인하였다. 해당 계산 조건의 경우 왼쪽 와도 분포 에서 확인할 수 있듯이 구속 와류의 한 주기 $(T=0.04)$ 안에 Karman 와류의 주기 $(T=0.008)$ 가 5 번 반복됨을 확인할 수 있다. 다 만 수치해석을 통한 수증기 체적분율 분포와 실험에서 발생한 공 동의 형상을 비교하였을 때 수치해석 결과는 쐐기 후류로 떨어져 나가는 보텍스 중심에서 발생하는 공동을 모사하지는 못하고 있 는데, 터널 내부 압력 및 속도장은 유사하게 모사됨을 고려하였 을 때 캐비테이션 모델에서의 질량 손실에 대한 보다 면밀한 고 려가 더 필요할 것으로 보인다.

또한 쐐기의 중심선을 따라 추출한 와도의 세기 분포를 살펴 보았을 때(Fig. 10), 한주기가 반복되는 $T=0.000$ 과 $T=0.040$ 의 결 과가 쐐기 폭의 1 배되는 동일한 지점에서 와도의 최대치를 갖
는 것을 확인할 수 있으며, 계산된 각각의 결과가 Karman 와류 가 반복되는 주기이므로 후류영역 전반에 걸친 와도 분포가 동 일함을 확인할 수 있다.

Fig. 11은 구속 와류와 박리 와류의 특성을 보다 면밀하게 평 가하기 위해 서로 다른 캐비테이션수 조건에서 발생하는 변동 압력을 분석하여 주기적인 특성을 비교하였다. Fig. 11(a)와 같 이 쐐기의 끝단이 위치한 관측창 상부에서 계측된 변동압력을 Fig, 11(b)와 같이 고속 푸리에 변환(FFT, fast Fourier transform) 을 통해 주파수영역의 소음수준(Sound pressure level, SPL)으로 변환하여 나타내었다. 수치해석 결과 또한 실험과 같은 위치에 서의 변동압력 값을 주파수영역의 소음수준으로 변화하여 비교 하였다. 그 결과 상대적으로 낮은 주파수와 높은 주파수 특성이 명확하게 분리되어 나타나는 것을 확인할 수 있다. 캐비테이션 수가 낮아질수록 먼 후류영역에서 발생하는 Karman 와류의 박 


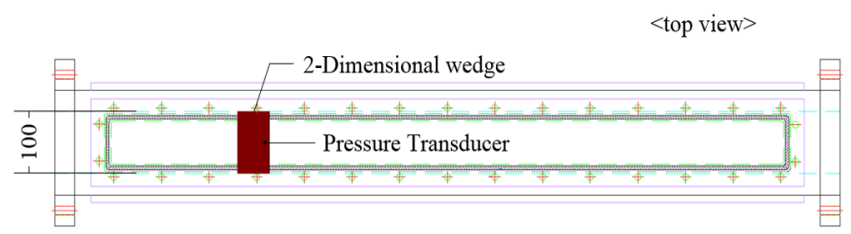

(a) test set-up

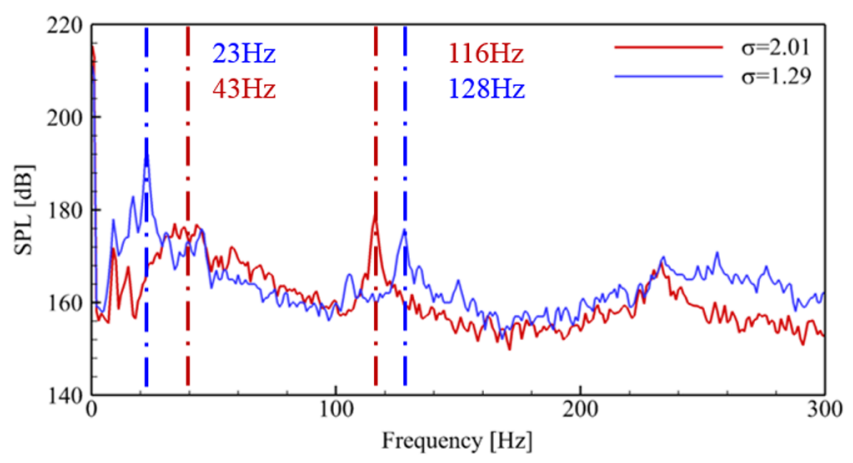

(b) Experimental measurements

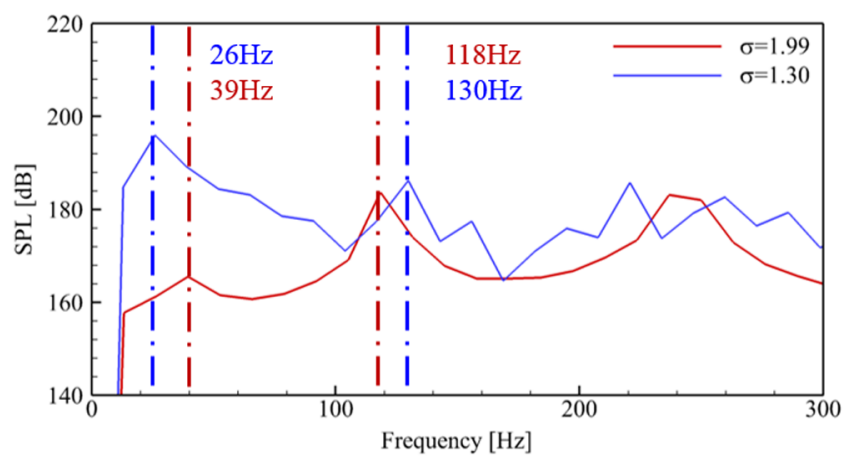

(c) Numerical results

Fig. 11 Sound pressure level in the frequency domain

리 주기는 짧아지며, 즉 주파수는 커지며, 가까운 후류영역에서 발생하는 구속 와류는 공동의 길이가 증가함에 따라 주기가 커 지기 때문이며, 수치해석 결과 또한 이러한 특성을 잘 보여주고 있다. 이러한 주파수 특성을 면밀히 비교하기 위해 다음 식 (13) 으로 정의되는 Strouhal수 $\left(S_{t}\right)$ 를 사용하여 비공동 상태의 후류와 공동 상태의 후류에서 발생하는 주파수 특성을 평가하였다.

$$
S_{t}=\frac{f d}{V_{\infty}}
$$

여기서 $f$ 는 주파수, $d$ 는 쐐기의 폭, $V_{\infty}$ 는 유동속도이다. Fig. 12 는 캐비테이션수에 따라 나타나는 Karman 와류의 주파수 특성을 Strouhal수로 나타낸 결과로, 비공동 상태일 때의 Strouhal수는 약 0.28 로 일정하게 유지되다가 캐비테이션이 발생하면 그 값은 약 $18 \%$ 정도 증가하였다가 다시 감소하는 것을 확인할 수 있다. 그 최대값은 캐비테이션수 $(\sigma)$ 1.29에서 나타났으며, 이때 구속 와류 에서 생성된 공동의 길이가 쐐기의 폭 $(d)$ 과 일치함을 확인하였 다. 이후 캐비테이션수가 낮아짐에 따라 Karman 와류의 박리 주 파수는 비공동 상태와 같아지는 것을 알 수 있다. 비공동 상태에 서는 유속 변화에 상관없이 일정하게 유지되는 Karman 와류의

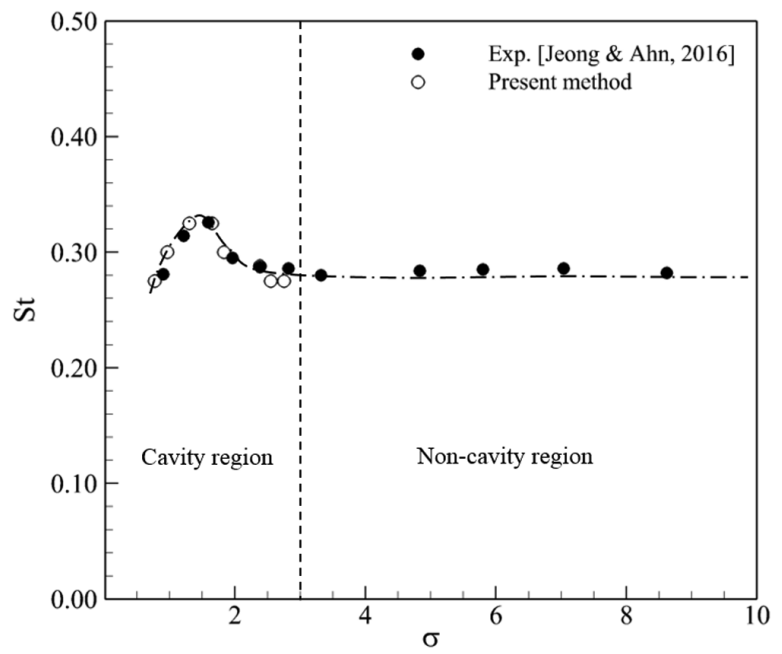

Fig. 12 Strouhal number versus cavitation number

Strouhal수는 공동이 발생하면서 구속 와류영역에서 발생하는 공 동의 영향으로 증가하는 특성을 확인 하였다. 즉, 일반적으로 잘 알려져 있는 바와 같이 비공동 상태에서는 유속 변화에 상관없이 일정하게 나타나는 Karman 와류의 박리 주파수 특성은 공동에 의해 큰 영향을 받으며 무엇보다 구속 와류의 성장과 밀접한 관 련이 있음을 알 수 있다.

\section{4. 결 론}

본 연구는 2차원 쐐기형 몰수체 후류에서 발생하는 비정상 공동 유동장을 해석하여 공동 발생에 따라 달라지는 박리 와류 의 주기특성 변화를 평가하고자 하였다. 이를 위해 상용프로그 램인 STAR-CCM+를 사용하여 비정상 공동유동 해석을 수행하 였으며, 충남대학교 캐비테이션 터널 실험 결과와 비교, 검증하 였다. 본 연구를 통해 2차원 몰수체에서 발생하는 Karman 와류 의 주기적 특성은 공동의 발생정도에 따라 큰 영향을 받으며, 특히 구속된 공동의 길이가 쐐기의 폭만큼 성장하였을 가장 크 게 나타난다는 것을 규명하였다.

\section{후기}

본 연구는 한국연구재단 원천기술개발사업(NRF-2014M3C1A 9060786), 산업통상자원부의 산업융합원천기술개발사업(1004 5337) 과 산업핵심기술개발사업(10062293)의 지원으로 수행된 연구결과 중 일부임을 밝히며, 연구비 지원에 감사드립니다.

\section{References}

Ahn, B.K., Lee, C.S., Kim, H.T., 2010. Experimental and Numerical Studies on Super-Cavitating Flow of Axisymmetric Cavitators. International Journal of Naval Architecture and Ocean Engineering, 2(1), 39-44.

Ahn, B.K., Lee, T.K., Kim, H.T., Lee, C.S., 2012. Experimental Investigatino of Supercavitating Flows. International Journal 
of Naval Architecture and Ocean Engineering, 4(2), 123-131. Belahadji, B., Franc, J.P., Michel, J.M., 1995. Cavitation in the Rotational Structures of a Turbulent Wake. Journal of Fluid Mechanics, 287, 383-403.

Franc, J.P., Michel, J.M., 2004. Fundamentals of Cavitation. Kluwer Academic Publishers, Dordrecht, The Netherlands.

Jeong, S.W., Ahn, B.K., 2016. An Experimental Study on Wake Cavity Flow Characteristics of Two-dimensional Wedge Shaped Control Fin. Journal of the Society of Naval Architect of Korea, 53(3), 180-187.

Kim, J.H., Jang, H.K., Ahn, B.K., Lee, C.S., 2013. A Numerical Analysis of the Supercavitating Flow around Three-Dimensional Axisymmetric Cavitators. Journal of the Society of Naval Architects of Korea, 50(3), 160-166.

Kim, J.H., Jeong, S.W., Ahn, B.K., Jeon, Y.H., 2016. A Study on Natural Supercavitation and Drag Characteristics of Axisymmetric Cavitators. Journal of the Society of Naval Architect of Korea, 53(6), 465-472.

Ozgoren, M., Yagmur, S., Dogan, S., Aksoy, M.H., Canli, E., Goktepeli, I., 2015. Flow Characteristics around a Vortex Flow Meter via CFD and PIV Methods. Proceedings of $10^{\text {th }}$ Pacific Symposium on Flow Visualization and Image Processing, Naples Italy.

Ramamurthy, A.S., Balachandar, R., 1990. The Near Wake Characteristics of Cavitating Bluff Sources. Transactions of the ASME, 112, 492-495.

Schnerr, G.H., Sauer, J., 2001. Physical and Numerical Modeling of Unsteady Cavitation Dynamics. Proceedings of $4^{\text {th }}$ International Conference on Multiphase Flow, New Orleans USA.

Siemens, 2016. STAR-CCM+ User Guide. Version 11.06. 